Check for updates

Cite this: RSC Adv., 2017, 7, 52719

Received 9th August 2017

Accepted 8th November 2017

DOI: $10.1039 / c 7 r a 08812 d$

rsc.li/rsc-advances

\section{Comparison of chemical, ultrasonic and thermal regeneration of carbon nanotubes for acetaminophen, ibuprofen, and triclosan adsorption $\dagger$}

\author{
Yifei Wang, (D) a Xiuming Wei, ${ }^{a}$ Ruochu Zhang, ${ }^{a}$ Yingfeng Wu, ${ }^{a}$ \\ Muhammad Usman Farid ${ }^{b}$ and Haiou Huang ${ }^{\star a c}$
}

Recovering the adsorption capacity of multi-walled carbon nanotubes (MWCNT) is of importance to the sustainable use of MWCNT for the adsorption of pharmaceuticals and personal care products (PPCP). In this study, different regeneration approaches, including chemical desorption, sonication, and thermal treatment were compared for their efficiencies in regenerating the adsorption capacities of a MWCNT for acetaminophen (AAP), ibuprofen (IBU), and triclosan (TCS). Among chemical solutions possessing different levels of hydrophobicity, $\mathrm{pH}$ and salt concentrations, a $\mathrm{NaCl}$ solution a concentration of $0.1 \mathrm{M}$ outperformed others due to the replacement of the adsorbed PPCP by $\mathrm{Na}^{+}$, and hence regenerated the used MWCNT. However, the higher desorption ratio of TCS and IBU (mainly governed by $\pi-\pi$ interactions) than that of AAP (dominated by hydrogen-bonding interactions) was due to the smaller bond interactions of $\pi-\pi$ interactions than hydrogen-bonding interactions. Furthermore, sonication of the MWCNT immersed in the NaCl solution increased the adsorption capacities of MWCNT by $4.9-33.7 \%, 36.8-46.9 \%$ and $1.1-6.8 \%$ for AAP, IBU, and TCS, respectively, possibly because the highenergy pulsation induced by sonication weakened the adhesive interaction between MWCNT and PPCP. Furthermore, thermal regeneration of the MWCNT at $380{ }^{\circ} \mathrm{C}$ led to the vaporization and/or oxidation of the adsorbed PPCP, while it maintained the characteristics of the MWCNT. Overall, these results imply that thermal regeneration is potentially the most effective approach for regenerating MWCNT.

\section{Introduction}

As an important class of emerging contaminants, pharmaceutical and personal care products (PPCP) have drawn broad attention due to their high consumption in modern society and frequent release into the environment. ${ }^{1} \mathrm{~A}$ variety of carbonaceous materials have been applied for the adsorption of PPCP and other organic pollutants, such as activated carbon, ${ }^{2}$ graphene, ${ }^{3}$ fullerene, ${ }^{4}$ and single-/multi-walled carbon nanotubes (SWCNT/MWCNT). ${ }^{5}$ Among them, MWCNT have been most widely studied due to abundant pore structures, small diameters, large specific surface areas, and good antibacterial

\footnotetext{
${ }^{a}$ State Key Joint Laboratory of Environmental Simulation and Pollution Control, School of Environment, Beijing Normal University, No. 19, Xinjiekouwai Street, Beijing 100875, China. E-mail: huanghaiou@bnu.edu.cn; Fax: +86 105880 7743; Tel: +86 1058807743

${ }^{b}$ School of Energy and Environment, City University of Hong Kong, Tat Chee Avenue, Kowloon, Hong Kong, China

${ }^{c}$ Department of Environmental Health Sciences, Bloomberg School of Public Health, John Hopkins University, 615 North Wolfe Street, MD 21205, USA

$\dagger$ Electronic supplementary information (ESI) available. See DOI: 10.1039/c7ra08812d
}

properties. ${ }^{6}$ However, current market prices of MWCNT range between \$100-45 $000 \mathrm{~kg}^{-1}$ as compared to those of $\$ 0.67-75 \mathrm{~kg}^{-1}$ for activated carbon..$^{7-9}$ Due to the relatively high cost of CNT and chemical pollution produced by the used CNT, effective methods to regenerate the adsorption capacity of MWCNT are immediately sought for sustainable use of MWCNT as adsorbents in environmental applications.

At present, methods for adsorbent regeneration include thermal regeneration, ${ }^{\mathbf{1 0}}$ chemical regeneration, ${ }^{\mathbf{1 1}}$ bio-regeneration, ${ }^{12}$ and microwave radiation regeneration. ${ }^{13}$ Among them, chemical desorption has been widely studied for the regeneration of CNT adsorbents. According to the literature, four major types of solute-CNT interactions govern the adsorption/ desorption of organic contaminants on CNT; these interactions include $\pi-\pi$ bond interactions, electrostatic interactions, hydrophobic interactions, and hydrogen-bonding interactions. ${ }^{\mathbf{1 4}, 15}$ Effective chemical regeneration methods may be developed by altering these interactions to enhance desorption of adsorbate. For example, dipolar solvents such as methanol and ethanol can reduce the attractive hydrophobic interaction between organics and CNT, which has been used to desorb dyes from CNT. ${ }^{16}$ Moreover, variations in solution $\mathrm{pH}$ were found to 
affect the strength of hydrogen bonds between PPCP and CNT to affect PPCP adsorption/desorption; ${ }^{17}$ this effect may be applied to desorb PPCP from CNT.

In addition to chemical regeneration, sonication of CNT in aqueous suspension has been studied for recovering PPCP from CNT adsorbents. According to Feng et al. ${ }^{18}$ ultrasonic treatment was efficient in desorbing tetracycline and carbamazepine from MWCNT. In principle, sonication may weaken the cohesive interaction between CNT and aqueous chemicals through highenergy pulsation and/or pyrolysis-induced adsorbate collapse and fragmentation. These effects are affected by the ultrasonic frequency ${ }^{19}$ and an optimum frequency of $60 \mathrm{kHz}$ has been found in a previous study. ${ }^{20}$

Thermal treatment has also been investigated in limited studies for the regeneration of CNT adsorbents. Wei et al. ${ }^{10}$ found that thermal treatment at $400{ }^{\circ} \mathrm{C}$ recovered the adsorption capacity of an exhausted carbon nanotube for diclofenac sodium and carbamazepine (CBZ) by $62-78 \%$ and $65-72 \%$, respectively, after ten reuse cycles. Compared with chemical desorption, thermal regeneration directly decompose organic adsorbates without the use of any chemicals. ${ }^{21}$

Despite the aforementioned findings in the literature, there is currently not any systematic report on the efficiencies of different regeneration methods under conditions relevant to the application of MWCNT in advanced water/wastewater treatment. This research gap has largely hindered full-scale applications of CNT to water treatment and environmental remediation. Therefore, this study aimed to investigate CNT regeneration under selected chemical, ultrasonic, and thermal conditions, for the adsorption of selected PPCP compounds. The results demonstrate that thermal treatment is the most efficient approach for CNT regeneration and worthy of future investigation under broad application conditions.

\section{Experimental section}

\subsection{Chemicals and carbon nanotubes}

Reagent-grade triclosan (TCS), ibuprofen (IBU), acetaminophen (AAP) were purchased from Tokyo Chemical Industry Co., Ltd, Japan. These chemicals were selected due to their high detection rates and levels in natural waters in Northern China. ${ }^{22,23}$ The physiochemical properties of these chemicals are listed in Table 1. The PPCP chemicals were dissolved into HPLC-grade methanol (Fisher Scientific, USA) to prepare stock solutions of $1000 \mathrm{mg} \mathrm{L}^{-1}$ for AAP, $250 \mathrm{mg} \mathrm{L}^{-1}$ for IBU, and $500 \mathrm{mg} \mathrm{L}^{-1}$ for TCS. Other chemicals used in the study were all reagent-grade and purchased from Beijing Fine Chemical Co., Ltd., China.

MWCNT employed in this study was purchased from Beijing Boyu Technology Corporation of High-tech New Materials, China. Characteristics of the MWCNT were determined by using approaches specified below and the results are summarized in Table S1. $\dagger$ It is noteworthy that the MWCNT samples possessed only moderate adsorption capacities for the studied PPCP compounds among a group of commercially available CNT products that we have evaluated (Fig. S1, ESI $\dagger$ ), but were employed herein because they allowed evaluation of the regeneration efficiency in a relatively short period.

\subsection{Preparation of the MWCNT adsorbent}

Prior to each adsorption experiment, $30 \mathrm{mg}$ of MWCNT were weighted with a digital microbalance (FA2004, Soptop, China) and dispersed in $30 \mathrm{~mL}$ of ultrapure water. After sonicating for 30 min with a water-bath sonicator (KQ5200DE, Kunshan Shumei Corp., China), the MWCNT dispersion was drawn into a plastic syringe and pushed slowly through a flat-sheet, polyvinylidene fluoride (PVDF) membrane (Durapore ${ }^{\circledR}$ HVLP, Millipore, USA) with a nominal pore size of $0.22 \mu \mathrm{m}$ and an effective membrane area of $4.52 \times 10^{-4} \mathrm{~m}^{2}$. The CNT retained on the membrane surface was then continuously rinsed with ultrapure

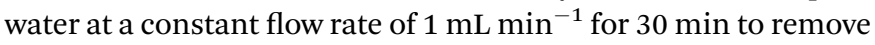
soluble impurities on the CNT and the PVDF membrane.

\subsection{Chemical regeneration}

In the preliminary experiments, a four-cycle, filtration-regeneration experiment was conducted with a bench-scale filtration system illustrated in Fig. S2. $\dagger$ Specifically, prior to the regeneration experiment, a feed solution containing $1 \mathrm{mg} \mathrm{L}^{-1}$ of AAP, IBU, or TCS was prepared by diluting the PPCP stock solutions into an electrolyte solution consisting of $0.01 \mathrm{M} \mathrm{NaCl}$ and at an adjusted $\mathrm{pH}$ of 7.0. During the first filtration-regeneration cycle, the feed solution containing $1 \mathrm{mg} \mathrm{L}^{-1}$ of PPCP was filtered through the CNT-loaded PVDF membrane for $45 \mathrm{~min}$. Dynamic adsorption of the PPCP by the CNT was monitored by online measurement of the UV absorbance of PPCP in the filtrate. Subsequently, the CNT membrane was rinsed with $30 \mathrm{~mL}$ of a solution containing $0.1 \mathrm{M}$ of $\mathrm{NaCl}$ and having a $\mathrm{pH}$ of 7 . During the second cycle, the efficacy of the first regeneration was assessed with the filtration of the feed solution for another $45 \mathrm{~min}$. Then after, the MWCNT was rinsed with $30 \mathrm{~mL}$ of $50 \%$ (vol\%) methanol. The third cycle was performed with the filtration of the feed solution, followed with CNT regeneration with $50 \%$ (vol\%) ethanol solution. Finally, the fourth cycle was conducted with the feed solution to assess the regeneration efficacy of ethanol solution. The flow rates of the feed water and the rinsing solutions were fixed at $1 \mathrm{~mL} \min ^{-1}$ throughout the experiment.

The efficacy of chemical regeneration was evaluated based upon variations in the adsorption capacity of MWCNT after chemical regeneration, benchmarked to that of the pristine MWCNT. The filtration-regeneration experiment was conducted with a bench-scale filtration system illustrated in Fig. S2. $\dagger$ Specifically, prior to the regeneration experiment, a feed solution containing $1 \mathrm{mg} \mathrm{L}^{-1}$ of AAP, IBU, or TCS was prepared by diluting the PPCP stock solutions into an electrolyte solution consisting of $0.01 \mathrm{M} \mathrm{NaCl}$ and at an adjusted $\mathrm{pH}$ of 7.0. During the first filtration-regeneration cycle, the feed solution containing $1 \mathrm{mg} \mathrm{L}^{-1}$ of PPCP was filtered through the CNT-loaded PVDF membrane for $45 \mathrm{~min}$. Dynamic adsorption of the PPCP by the CNT was monitored by online measurement of the UV absorbance of PPCP in the filtrate. Subsequently, the CNT membrane was rinsed with $30 \mathrm{~mL}$ of a solution containing $0.1 \mathrm{M}$ of $\mathrm{NaCl}$ and having a $\mathrm{pH}$ of 7 . After that, the efficacy of the first regeneration process was assessed with the filtration of the feed solution for another $45 \mathrm{~min}$. 
Table 1 Physico-chemical properties of acetaminophen, ibuprofen and triclosan

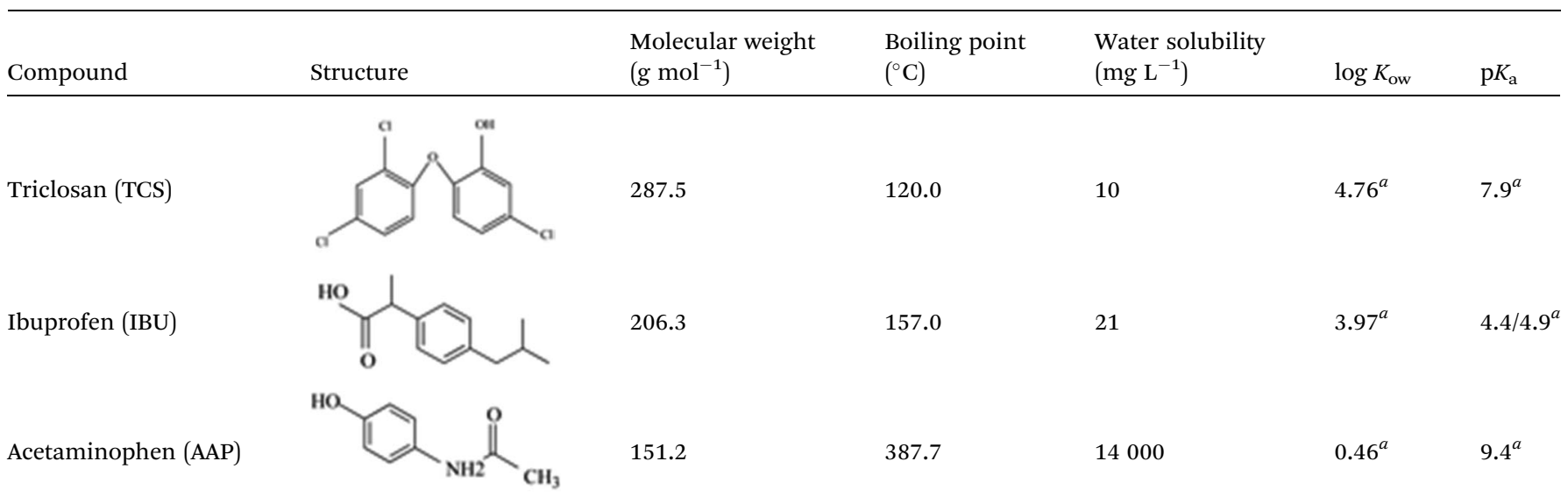

\footnotetext{
${ }^{a}$ P. Westerhoff, Y. Yoon, S. Snyder, E. Wert, Fate of endocrine-disruptor, pharmaceutical, and personal care product chemicals during simulated drinking water treatment processes, Environmental Science \& Technology, 39 (2005) 6649-6663.
}

\subsection{Ultrasonic regeneration}

A dual-channel membrane filtration system was employed for paired testing of CNT regeneration with and without sonication (Fig. 1). During each experiment, two similar CNT filters were installed in parallel onto the dual-channel filtration system. The feed solution was filtered simultaneously through the two filters

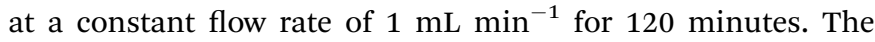
filtrate was collected at regular intervals for the measurement of PPCP concentration. Afterwards, the used membrane filters were immediately placed into two separate glass beakers, each having $30 \mathrm{~mL}$ of $0.1 \mathrm{M} \mathrm{NaCl}$ solution. One of the two beakers with the membrane filter was placed into the aforementioned water bath sonicator and sonicated at a frequency of $40 \mathrm{kHz}$ for 15-60 min. The other beaker with the control filter was kept quiescently in the $0.1 \mathrm{M} \mathrm{NaCl}$ solution for the same period.

After determining a suitable ultrasonic time, multi-cycle experiments with ultrasonic regeneration were carried out for five consecutive cycles to investigate the variations in the adsorption capacity of the CNT for the targeted PPCP compound after multiple regeneration steps. All dynamic adsorption and regeneration experiments were conducted at a room temperature of $25 \pm 2{ }^{\circ} \mathrm{C}$ and repeated at least twice to validate the repeatability of the results.

\subsection{Thermal regeneration}

Given a melting point of $c a .177^{\circ} \mathrm{C}$ for PVDF, loading MWCNT onto the PVDF membrane would result in damage to the PVDF material during the thermal regeneration process. Therefore, the efficacy of thermal regeneration was not assessed based upon dynamic filtration experiments as used for chemical and ultrasonic regeneration studies, but instead, by the static adsorption method described below. Specifically, during each batch of static adsorption experiments, $30 \mathrm{mg}$ of MWCNT were massed and added into a series of amber glass vials, each

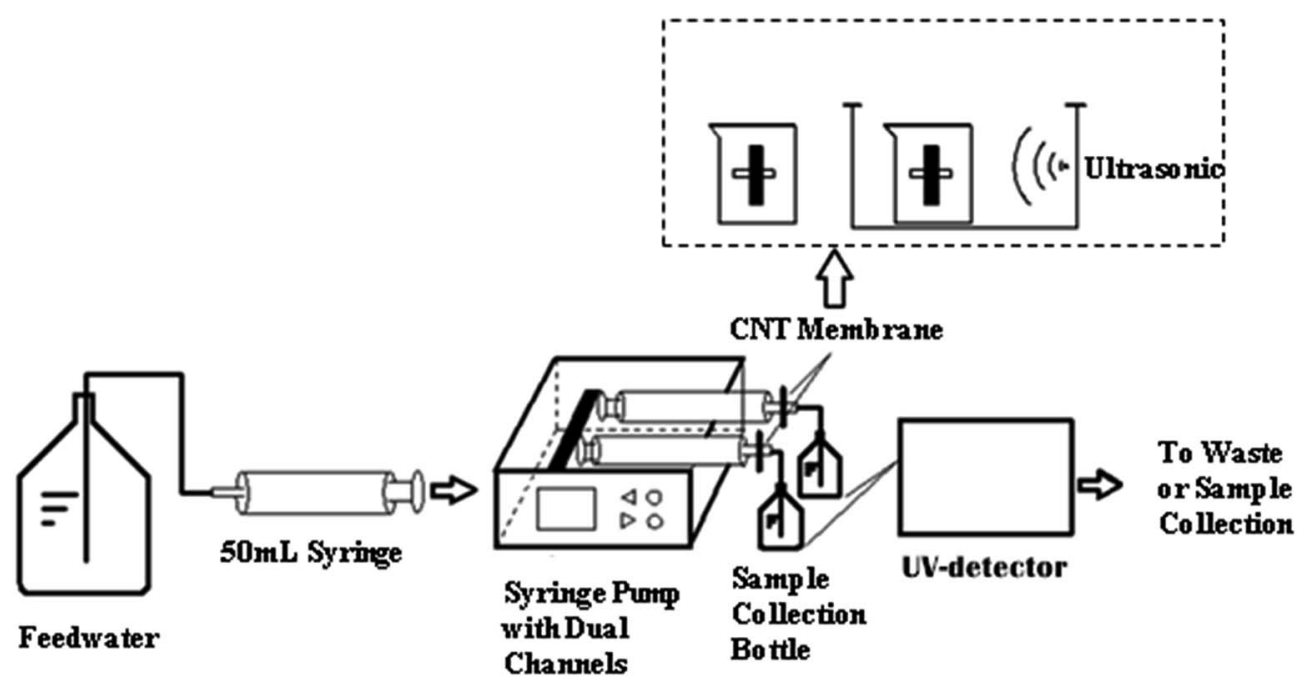

Fig. 1 A schematic diagram of the bench-scale membrane filtration system employed in the ultrasonic regeneration experiments. 
containing $120 \mathrm{~mL}$ of PPCP solution at a preset initial concentration of $1 \mathrm{mg} \mathrm{L}^{-1}$. The vials were then sealed with caps lined with PTFE and mixed by end-over-end rotation in the dark, at an ambient temperature of $25 \pm 2{ }^{\circ} \mathrm{C}$ for $99 \mathrm{~h}$. In the end of the adsorption experiment, the MWCNT was separated from the solution by a PVDF membrane and dried in air. Subsequently, thermal regeneration of MWCNT was operated by treating the used and dried MWCNT sample at $380{ }^{\circ} \mathrm{C}$ inside a muffle oven (SX-G36123, Tianjin, China) for $2 \mathrm{~h}$. This heating temperature was determined based upon the boiling points of the PPCP compounds (Table 1) and the thermal stability of the MWCNT (Fig. S3, ESI $\dagger$ ). After the thermal treatment, the adsorption capacity of the regenerated MWCNT was determined in another batch of static adsorption experiments following the aforementioned protocol. As such, the efficacy of thermal regeneration was assessed based upon the difference in adsorption capacities between the original and the regenerated CNT sample. The adsorption-regeneration process was repeated for five consecutive cycles to investigate long-term effects of thermal treatment on the properties and the adsorption capacities of MWCNT for PPCP compounds.

\subsection{Analytical methods}

Surface chemical composition and functionality of the MWCNT samples before and after regeneration treatments were determined by a X-ray photoelectron spectroscope (XPS, ESCALAB 250Xi, USA) and a Fourier transform infrared spectroscope (FTIR) (Nexus670, Nicolet, USA). For Brunauer-Emmett-Teller (BET) measurements of the specific surface area (SSA), $\mathrm{N}_{2}$ adsorption data at $77 \mathrm{~K}$ were obtained using a high-resolution gas adsorption analyzer with high vacuum capacity $\left(5 \times 10^{-7} \mathrm{~Pa}\right)$ (autosorb iQ, Quantachrome), following the standard method for black carbon samples. ${ }^{24}$ The air-dried specimens of the CNT loaded on the PVDF membrane were sputter-coated with gold and then imaged using a cold cathode field emission scanning electron microscope (SEM) (HITACHI S-4800) at $10 \mathrm{keV}$. Transmission electron microscopy (TEM) images of the MWCNT samples before and after the regeneration treatment were acquired with a FEI TF20 TEM at an accelerating voltage of $200 \mathrm{kV}$. Moreover, the UV absorbance of the feed solution, the permeate, and the regeneration wastewater was measured using a UV-vis spectrophotometer (HACH DR 6000) at wavelengths of $220 \mathrm{~nm}$ for TCS and IBU, $242 \mathrm{~nm}$ for AAP, respectively, to determine the concentrations of these compounds. To determine the thermal stability of MWCNT, $10 \mathrm{mg}$ MWCNT were prepared in the aluminium oxide pans at a heating rate of $10{ }^{\circ} \mathrm{C} \mathrm{min}^{-1}$ to $1100{ }^{\circ} \mathrm{C}$ in an atmosphere of air flowing at $180 \mathrm{~mL} \mathrm{~min}^{-1}$ by the Thermogravimetric Analyzer (HTC3).

\subsection{Computing methods}

Herein, the adsorption capacity $(q)$ was defined as the ratio of the total mass of PPCP adsorbed and the total mass of the MWCNT. Because the total mass of CNT loaded on each membrane, $m_{\mathrm{CNT}}$, was preset at $30 \mathrm{mg}$, the surface concentration of PPCP on the MWCNT, $q\left[\mathrm{mg} \mathrm{g}^{-1}\right]$, is calculated with eqn (1):

$$
q=\frac{m_{\mathrm{PPCP}}}{m_{\mathrm{CNT}}}
$$

\section{Results}

\subsection{Effect of chemical solution conditions on MWCNT regeneration}

Chemical regeneration of MWCNT by $\mathrm{NaCl}$, methanol and ethanol solutions resulted in different adsorption capacities for the regenerated MWCNT sample. The adsorption capacities of MWCNT regenerated with the ethanol solution were the lowest for the three studied PPCP compounds (Fig. 2), followed by methanol. Overall, the regeneration performance of $0.1 \mathrm{M} \mathrm{NaCl}$ solution was better than that of ethanol or methanol.

Moreover, the regeneration efficacy of $\mathrm{NaCl}$ solution depended upon $\mathrm{NaCl}$ concentration. When $\mathrm{NaCl}$ concentration increased from 0 to $1.0 \mathrm{M}$, the adsorption capacity of MWCNT for AAP was the highest after regeneration with $0.1 \mathrm{M} \mathrm{NaCl}$ solution compared to that obtained with 0 or $1.0 \mathrm{M} \mathrm{NaCl}$ solution (Fig. S4, ESI $\dagger$ ). Therefore, considering the effectiveness in regeneration and the safety in water treatment operation, $0.1 \mathrm{M}$ $\mathrm{NaCl}$ solution was regarded as the most suitable regeneration solution for chemical regeneration of the MWCNT.

\subsection{Effect of sonication on MWCNT regeneration}

Because the power output of the sonicator was fixed in this study, sonication time was the only viable parameter during the ultrasonic regeneration. The adsorption capacities of the MWCNT for AAP generally increased as the sonication time increased from $15 \mathrm{~min}$ to $60 \mathrm{~min}$ (Fig. 3a-c). Moreover, the improvement in the regeneration performance was minor for IBU and TCS when the treatment time exceeded $30 \mathrm{~min}$. Therefore, $30 \mathrm{~min}$ was considered as a suitable time for the regeneration of MWCNT for IBU removal, while 60 min was chosen for AAP and TCS.

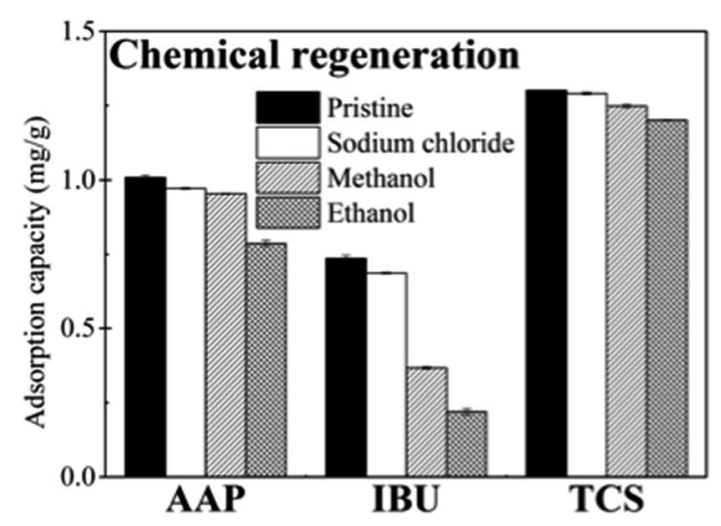

Fig. 2 Adsorption capacities of the MWCNT for acetaminophen, ibuprofen and triclosan in the pristine form and after the regeneration by $0.1 \mathrm{M} \mathrm{NaCl}$ solution, $50 \%$ (vol\%) methanol solution, and $50 \%$ (vol\%) ethanol solution, successively. Feed PPCP concentration $=1 \mathrm{mg} \mathrm{L}^{-1}$, $\mathrm{pH}=7.0$, cumulative permeate throughput $=62.3 \mathrm{~L} \mathrm{~m}^{-2}$, CNT mass $=$ $30 \mathrm{mg}$, temperature $=25 \pm 2{ }^{\circ} \mathrm{C}$. The error bars represent the upper and lower values obtained in duplicate experiments. 

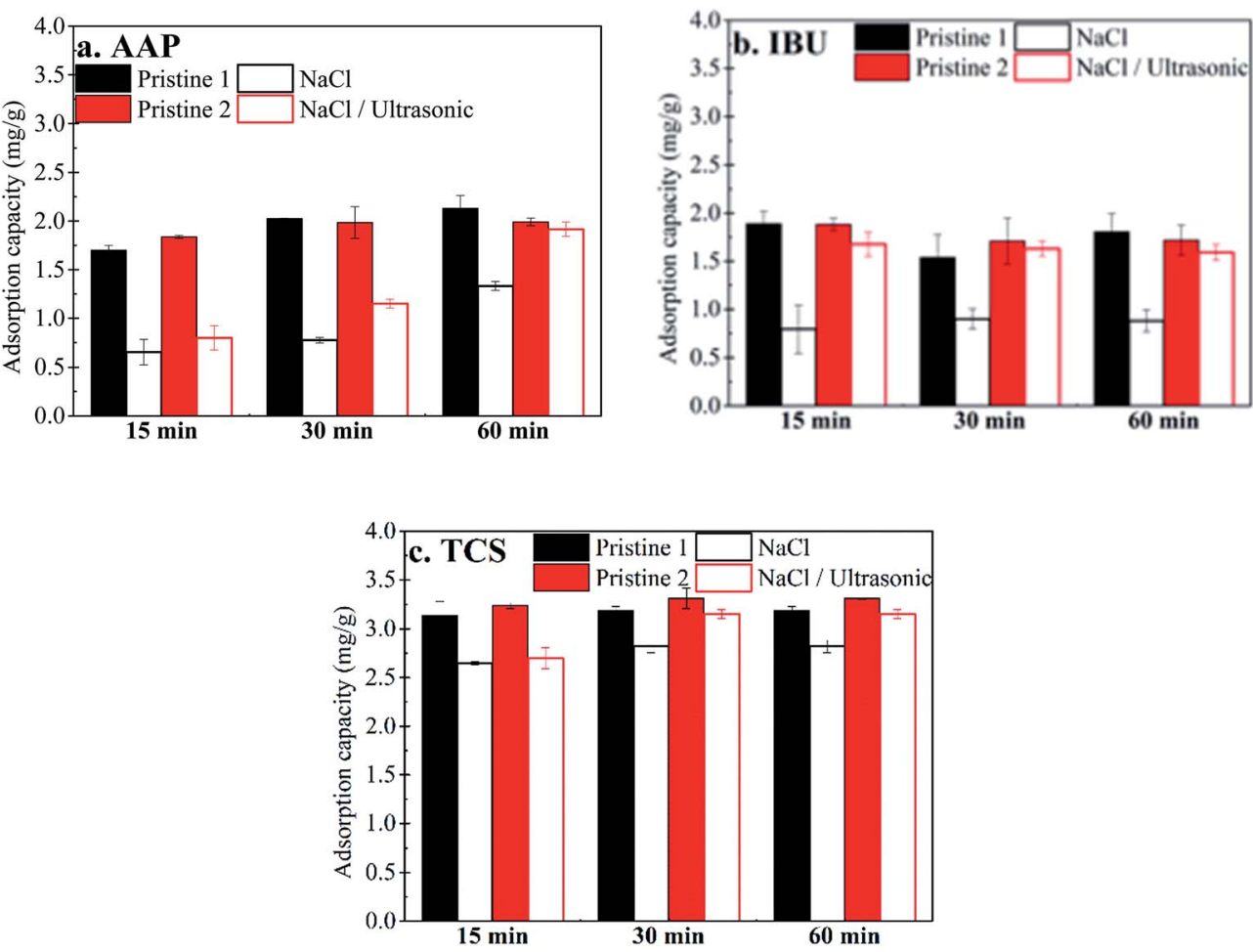

Fig. 3 Adsorption capacities of the MWCNT in the pristine form and after regeneration in $0.1 \mathrm{M} \mathrm{NaCl}$ solution with/without ultrasonic treatment, for AAP, IBU, and TCS, respectively. Feed concentration $=1 \mathrm{mg} \mathrm{L}^{-1}, \mathrm{pH}=7.0$, cumulative permeate throughput $=174 \mathrm{~L} \mathrm{~m}{ }^{-2}, \mathrm{CNT}$ mass $=30 \mathrm{mg}$, temperature $=25 \pm 2{ }^{\circ} \mathrm{C}$. The error bars represent the upper and lower values obtained in duplicate experiments.

At the optimal sonication condition, the adsorption capacity of the MWCNT for AAP reached $1.99 \mathrm{mg} \mathrm{g}^{-1}$ after regeneration or $96 \%$ of that of the pristine MWCNT sample, i.e., $2.13 \mathrm{mg} \mathrm{g}^{-1}$ (Fig. 3a). The ratios of recovery were $95 \%$ for IBU (Fig. 3b) and 95\% for TCS (Fig. 3c), respectively. Overall, the adsorption capacities of the MWCNT were effectively recovered by using the combination of ultrasonic treatment and chemical treatment.

Consistent with the results of adsorption capacity shown in Fig. 3, sonication time positively influenced PPCP desorption from the MWCNT in $0.1 \mathrm{M} \mathrm{NaCl}$ solution. The percentages of AAP and TCS desorbed generally increased with increasing sonication time, while those of IBU were relatively stable at $15 \mathrm{~min}$ and $30 \mathrm{~min}$, but slightly decreased at $60 \mathrm{~min}$. After chemical regeneration without sonication, more than $97 \%$, $87 \%$, and $80 \%$ of AAP, IBU and TCS remained on the MWCNT, respectively. Comparatively, $85 \%$ of AAP, $48 \%$ of IBU and $60 \%$ of TCS remained on the MWCNT with ultrasonic treatment. Therefore, ultrasonic treatment promoted the desorption of AAP, IBU and TCS by $13 \%, 44 \%$ and $20 \%$, respectively, but did not completely desorb these compounds from the MWCNT.

\subsection{Efficacy of chemical/ultrasonic regeneration during multi-cycle experiments}

As stated above, combining chemical and ultrasonic regeneration obviously enhanced PPCP desorption (Fig. S5, ESI†). To further verify the performance of chemical/ultrasonic regeneration, consecutive, multi-cycle filtration was conducted under similar regeneration conditions.
For AAP, the adsorption capacities of MWCNT in individual cycles decreased from $1.99 \mathrm{mg} \mathrm{g}^{-1}$ to $1.60 \mathrm{mg} \mathrm{g}^{-1}$, while the desorbed amount remained at $0.25-0.30 \mathrm{mg} \mathrm{g}^{-1}$ (Fig. S6, ESI†). In comparison, the adsorption capacity of the MWCNT for IBU was consistently lower than that for AAP, but the desorbed amount varied from $0.51-0.77 \mathrm{mg} \mathrm{g}^{-1}$, higher than that for AAP

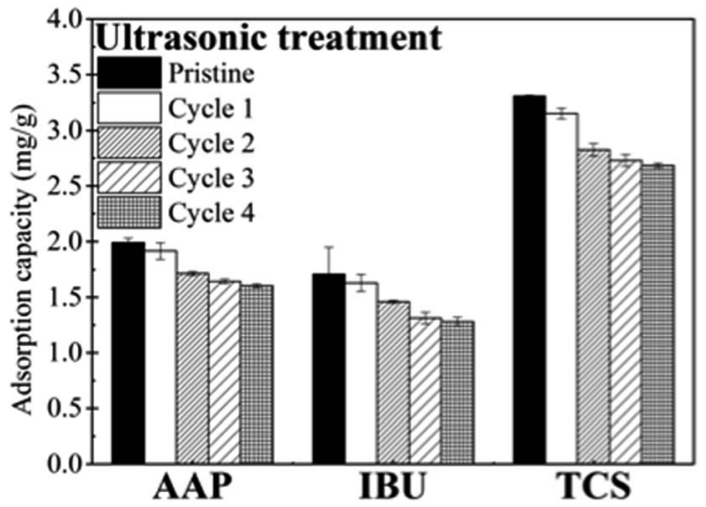

Fig. 4 Comparison of the adsorption capacities of the MWCNT for acetaminophen, ibuprofen and triclosan obtained in five consecutive regeneration circles with ultrasonic treatment at the optimal regeneration time. PPCP concentration in the feed solution = $1 \mathrm{mg} \mathrm{L}^{-1}, \mathrm{pH}=7.0$, cumulative permeate throughput $=174 \mathrm{~L} \mathrm{~m}^{-2}$, $\mathrm{CNT}$ mass $=30 \mathrm{mg}$, and temperature $=25 \pm 2{ }^{\circ} \mathrm{C}$. The error bars represent the upper and lower values obtained in duplicate experiments. 


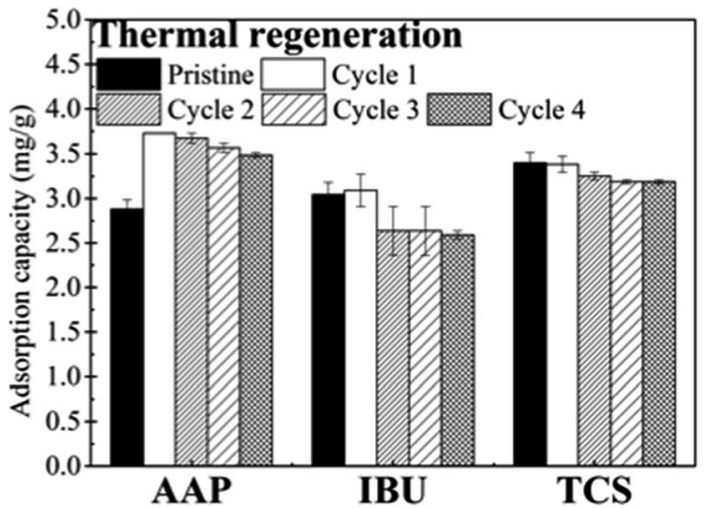

Fig. 5 Adsorption capacities of the MWCNT for AAP, IBU, and TCS obtained in five consecutive static adsorption circles. The MWCNT was regenerated at $380^{\circ} \mathrm{C}$ in air. $\mathrm{PPCP}$ concentration in the feed solution = $1 \mathrm{mg} \mathrm{L}^{-1}, \mathrm{pH}=7.0, \mathrm{CNT}$ mass $=30 \mathrm{mg}$, and adsorption temperature $=$ $25 \pm 2{ }^{\circ} \mathrm{C}$. The error bars represent the upper and lower values obtained in duplicate experiments.

(Fig. 4). For TCS, the adsorption capacity and desorbed amount were both higher than those of other compounds and reached 3.28 and $1.31 \mathrm{mg} \mathrm{g}^{-1}$, respectively. These results show the influence of PPCP properties on their adsorption and desorption during multi-cycle filtration by MWCNT.

Pertaining to temporal variations, the adsorption capacities of the MWCNT for all PPCP compounds decreased gradually as the filtration cycles proceeded (Fig. 4). Similar trends were observed for desorption amounts of the PPCP compounds (Fig. S6a, ESI $\dagger$ ). As a result, relatively stable desorption ratios were obtained for the three compounds; this trend was more obvious for AAP and TCS than for IBU. The desorption ratios of AAP and TCS remained at constant levels after the first cycle (Fig. S6b, ESI †े).

\subsection{Thermal regeneration of CNT}

The results obtained in five consecutive thermal regeneration circles are shown in Fig. 5. The adsorption capacities of MWCNT during the reuse cycles were higher than that of the pristine one; this was due to the purification of MWCNT during the thermal treatment. This finding was consistent with those of Wen et al. ${ }^{25}$ and Saini et al. ${ }^{26}$ For TCS, the adsorption capacities of the regenerated carbon nanotubes were $3.59-3.73 \mathrm{mg} \mathrm{g}^{-1}$ during the reuse cycles, resulting in 89.8-93.3\% removal of TCS from the feedwater, which was greater than $72.0 \%$ removal obtained by the pristine carbon nanotube. Similarly, the adsorption capacities of MWCNT for IBU and AAP were $2.59-3.09 \mathrm{mg} \mathrm{g}^{-1}$ and $3.19-3.83 \mathrm{mg} \mathrm{g}^{-1}$ in the reuse cycles, respectively, which corresponded to 87.1$93.2 \%$ and $64.8-77.3 \%$ removal of the two compounds, respectively.

\subsection{Effects of different regeneration conditions on MWCNT properties}

The adsorption capacities of MWCNT are related to their surface properties; the latter may be altered during chemical, ultrasonic, and thermal regeneration processes. Therefore, it is necessary to compare the properties of the MWCNT in its pristine form and after different regeneration processes. As shown in Fig. 6a-c, similar curved and granular CNT structures were observed under TEM, indicating that no significant structural change took place after chemical, ultrasonic and thermal regeneration processes used in this study. Furthermore, the XPS results revealed that the oxygen contents of the MWCNT in the pristine form and after chemical, ultrasonic and thermal regeneration were $2.1 \%, 3.1 \%, 2.2 \%$, and $2.9 \%$, respectively (Fig. 7 and Table 2). The minor increase in the oxygen content of MWCNT
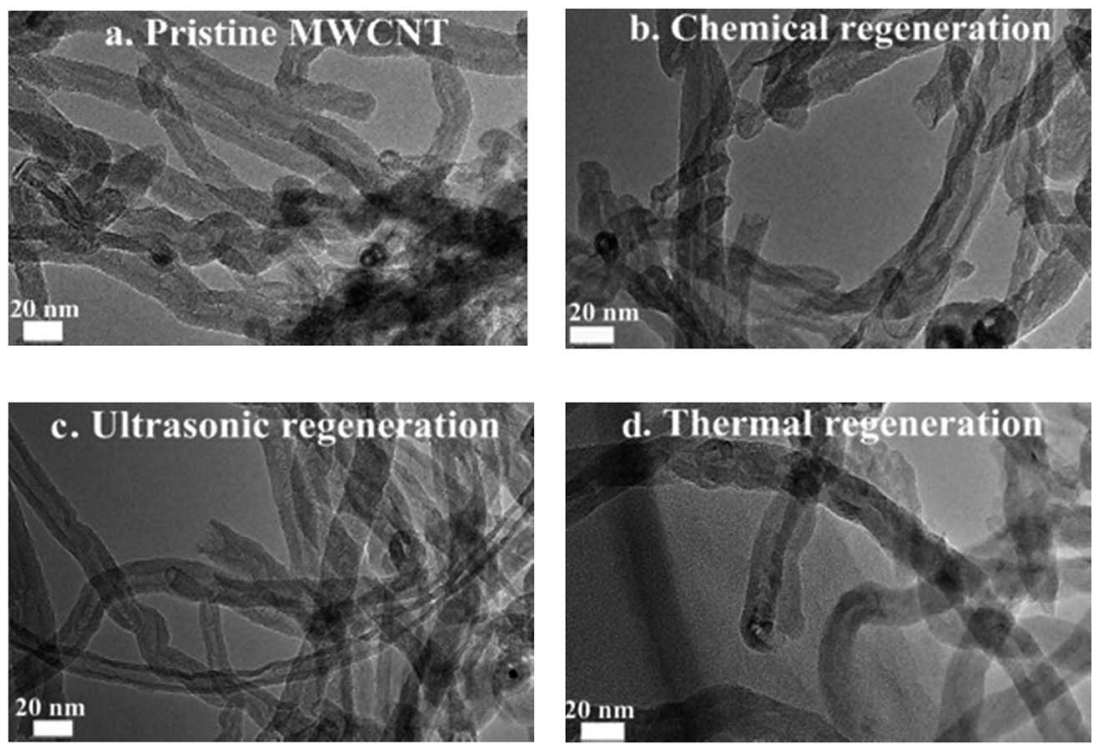

Fig. 6 Transmission electron microscope (TEM) images of (a) pristine MWCNT, (b) chemical regenerated MWCNT, (c) ultrasonic regenerated MWCNT, and (d) thermal regenerated MWCNT samples. 

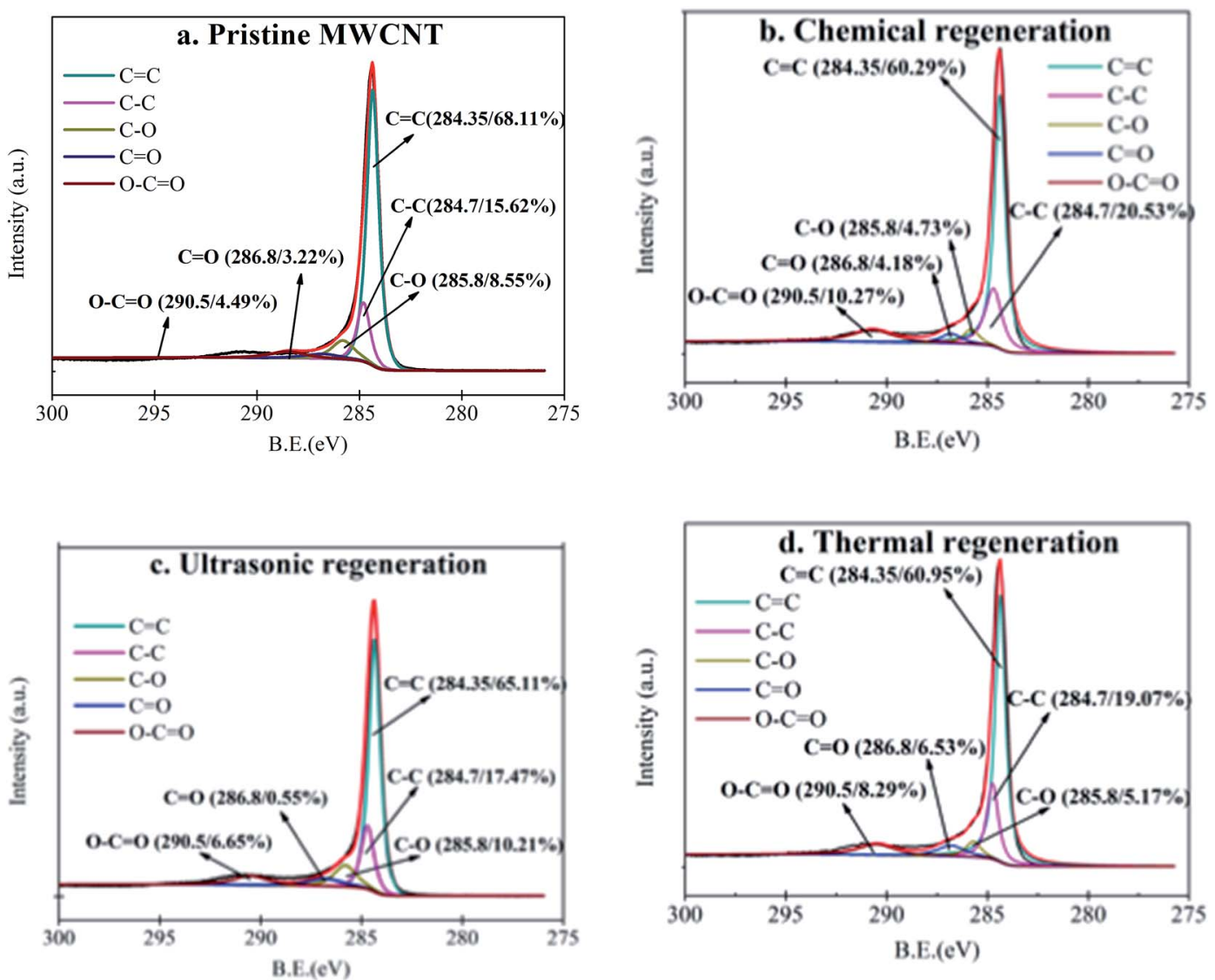

Fig. 7 XPS C 1s spectrum of (a) pristine MWCNT, (b) chemical regenerated MWCNT, (c) ultrasonic regenerated MWCNT, and (d) thermal regenerated MWCNT samples.

after regeneration was attributed to the formation of $\mathrm{C}-\mathrm{O}$, $\mathrm{O}=\mathrm{C}-\mathrm{O}$ and $\mathrm{C}-\mathrm{O}$ groups on MWCNT surfaces (Fig. 7). According to the results shown in Fig. S7, $\uparrow$ the main oxygenated functional groups on the pristine/regenerated MWCNT samples consisted of $\mathrm{C}=\mathrm{O}, \mathrm{C}=\mathrm{O}$ and $\mathrm{O}-\mathrm{C}=\mathrm{O}$. In comparison, no noticeable change in the surface composition of the MWCNT was found after the ultrasonic/chemical regeneration process. Overall, the MWCNT used in this study remained stable under all studied conditions.

Table 2 Chemical properties comparison for the pristine MWCNT and the MWCNT after chemical regeneration, ultrasonic regeneration and thermal regeneration

\begin{tabular}{lll}
\hline CNT type & $\begin{array}{l}\text { Surface oxygen } \\
(\%) \text { by XPS }\end{array}$ & $\begin{array}{l}\text { Specific surface } \\
\mathrm{area}^{b}\left(\mathrm{~m}^{2} \mathrm{~g}^{-1}\right)\end{array}$ \\
\hline MWCNT & $2.1^{a}$ & $137^{b}$ \\
Chemical regeneration & $3.1^{a}$ & $125^{b}$ \\
Ultrasonic regeneration & $2.2^{a}$ & $150^{b}$ \\
Thermal regeneration & $2.9^{a}$ & $136^{b}$ \\
a Data from the XPS analysis. & ${ }^{b}$ Data obtained using a high-resolution \\
gas adsorption analyzer with high vacuum capacity $\left(5 \times 10^{-7} \mathrm{~Pa}\right)$ \\
(autosorb iQ, Quantachrome).
\end{tabular}

\section{Discussion}

\subsection{General mechanisms for PPCP desorption from MWCNT}

The fundamental mechanisms for CNT regeneration are the enhanced desorption of the PPCP compounds under controlled physical and chemical conditions. As stated in the literature, four types of physico-chemical interactions, including $\pi-\pi$ bond interactions, electrostatic interactions, hydrophobic interactions, and hydrogen-bonding interactions govern CNT adsorption of PPCP compounds. ${ }^{27,28}$ As found in the previous studies, CNT adsorption of IBU and TCS is dominated by strong $\pi-\pi$ bond interactions between the PPCP molecules and the CNT surfaces, and this effect becomes stronger as the number of aromatic rings in PPCP structures increases. Furthermore, TCS adsorption may also be enhanced by hydrophobic interactions due to the strong hydrophobicity possessed by the compound. ${ }^{29}$ In comparison, hydrogen-bonding interaction plays an important role in AAP adsorption. ${ }^{22}$

Based upon the adsorption mechanism, the enhanced PPCP desorption observed during CNT regeneration should be related to the mitigation of the attractive interactions between PPCP compounds and CNT surfaces, i.e., $\pi-\pi$ bond and hydrophobic interactions for TCS, $\pi-\pi$ bond interactions for IBU, and hydrogen-bonding interaction for AAP. The detailed 
mechanisms will be elaborated below for each kind of regeneration method.

\subsection{Potential mechanisms of chemical regeneration}

Different chemical solutions should alter PPCP-CNT interactions based upon the nature of the interactions. Firstly, the use of methanol or ethanol solution reduces the polarity of the solvent phase as compared to water, which mitigates the hydrophobic interaction between the adsorbate and the MWCNT. This trend was indeed observed with TCS as the adsorption capacity of the MWCNT for TCS was recovered after regeneration with methanol or ethanol solution (Fig. 2). Secondly, unlike methanol or ethanol, sodium and chloride ions at moderate concentrations are capable of weakening PPCP-CNT interactions by replacing cationic or anionic adsorbates from CNT surfaces, thus enhancing adsorbate desorption. An analogue may be made with the elution effect observed in liquid chromatography (LC) analysis. Moderate concentration salt solutions are commonly used as the mobile phase to elute organic compounds from different types of LC columns to achieve the purpose of organic separation. For example, Chin et $a .^{30}$ and Zazouli et $a l .{ }^{31}$ used salt solutions as mobile phases to effectively separate humic substances and pharmaceutical compounds (cephalexin, tetracycline, acetaminophen, indomethacin and amoxicillin) for LC analysis. Therefore, when the used CNT were regenerated by $\mathrm{NaCl}$ solution, enhanced desorption of TCS, IBU, and AAP were observed (Fig. 8).

This "salting-out" effect is dependent of chemical properties of the adsorbate. After chemical regeneration with $\mathrm{NaCl}$ solution, the desorption ratio was $2.6 \%$ for AAP, $13.2 \%$ for IBU and $21.6 \%$ for TCS (Fig. S6 $\dagger$ ). The relatively low desorption of AAP may be due to existence of strong hydrogen bonding interaction between AAP and CNT surfaces. The absolute interaction energy was $2.3 \mathrm{kcal} \mathrm{mol}^{-1}$ for $\pi-\pi$ bond interactions ${ }^{32}$ as compared to the hydrogen-bonding interaction energy of $3.84 \mathrm{kcal} \mathrm{mol}^{-1} .^{33}$

\subsection{Potential mechanisms of ultrasonic-enhanced chemical regeneration}

In principle, sonication of liquids creates cavitation air bubbles. ${ }^{18,19}$ As the sonication proceeds, these air bubbles will grow in size and then collapse within a few microseconds. The violent collapse produces powerful hydromechanical shear forces at the adjacent water/solid interface, thereby enhancing the detachment or desorption of adsorbates from the solid surface. ${ }^{34,35}$ Moreover, high temperature and pressure produced inside the collapsing cavitation bubbles may also weaken the cohesive interaction between CNT and PPCP. ${ }^{36}$

As found in this study, when ultrasonic treatment was employed in combination with chemical regeneration, the desorption of AAP, IBU, and TCS was enhanced by $4.0-11.2 \%$, 27.4-38.8\% and 14.5-21.3\%, respectively (Fig. 3). Consistent with what stated above, the $\pi-\pi$ bond interaction governs the adsorption of IBU/TCS while hydrogen-bonding interaction is primarily responsible for AAP adsorption. The shear force formed during the ultrasonic treatment would counteract the $\pi-\pi$ bond interaction and the hydrogen-bonding interaction. The smaller interaction energy of $\pi-\pi$ bond interaction than the hydrogen-bonding interaction resulted in the greater enhancement in TCS and IBU desorption than AAP desorption. Moreover, the stronger attraction between TCS and CNT than that between IBU and CNT led to greater enhanced desorption of IBU than that of TCS. Consequently, the desorption ratio enhancement of ultrasonic treatment followed the order of IBU $>$ TCS $>$ AAP.

Previous studies also reported that sonication of CNT dispersion may cause oxidation of CNT surfaces by dissolved oxygen in water. ${ }^{37}$ The resultant sonochemical changes to CNT properties would alter the adsorption/desorption of organic compounds on CNT surfaces. However, the electron microscopic images (Fig. 6) and XPS results (Fig. 7) of this study both suggest that the surface properties of CNT remained unchanged after the ultrasonic regeneration process. Therefore, it is reasonable to deduce that the enhanced PPCP desorption observed in this study is primarily attributable to the aforementioned physical effects induced by collapsing air bubbles.

\subsection{Potential mechanisms of thermal regeneration}

Unlike the chemical or ultrasonic/chemical regeneration, thermal regeneration of the used MWCNT sample was conducted in air, instead of aqueous phase. Consequently, the desorption of PPCP from CNT surfaces took place between solid and gas phase. At a treatment temperature of $380{ }^{\circ} \mathrm{C}, \mathrm{PPCP}$ compounds were vaporised into the air. Due to the presence of oxygen in the air, some PPCP compounds may be further oxidized at the high temperature. As such, the adsorption capacity of CNT was effectively recovered for the three studied compounds (Fig. 5). This finding is in consistent with those reported in other studies. Wei et al. ${ }^{\mathbf{1 0}}$ found that thermal

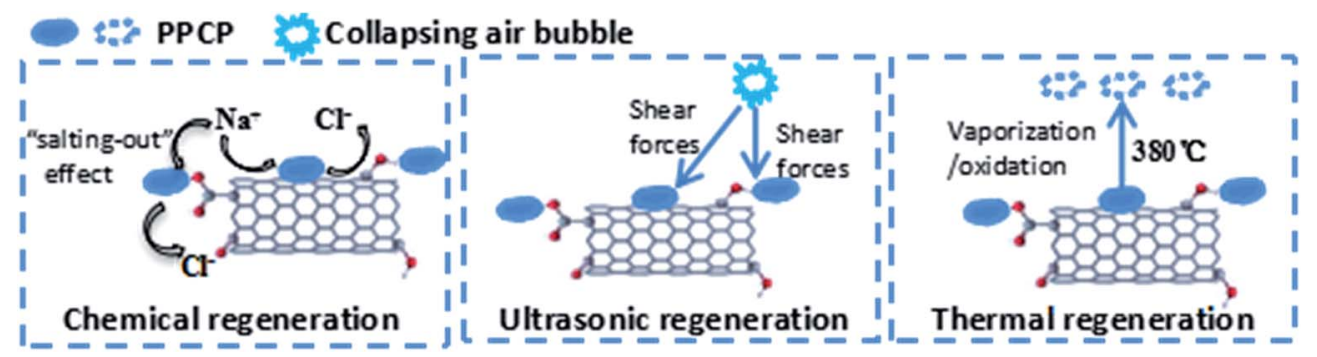

Fig. 8 The potential mechanism of chemical regeneration, ultrasonic regeneration and thermal regeneration. 
regeneration successfully desorbed carbamazepine (CBZ) from the CNT after ten reuse cycles, and the majority of the adsorbed CBZ compound was found to be oxidized during the thermal process.

Broadly speaking, the MWCNT used in this study was thermally stable (mass loss $<5 \%$ ) up to a heating temperature of $500{ }^{\circ} \mathrm{C}$, based upon the TGA results (Fig. S3, ESI†े), consequently, thermal regeneration may be conducted at temperatures higher than $380{ }^{\circ} \mathrm{C}$ but under $500{ }^{\circ} \mathrm{C}$ if the adsorption capacity for certain compounds cannot be recovered at $380^{\circ} \mathrm{C}$.

\subsection{Applicability of CNT regeneration for water treatment}

Among the three studied regeneration methods, chemical regeneration appeared to be effective only for lightly used MWCNT sorbent (Fig. 2), i.e., when the MWCNT adsorbed relatively small amounts of organic contaminants ( $c a$. 0.75$1.5 \mathrm{mg} \mathrm{g}^{-1}$ ). When the MWCNT adsorbed more organics, i.e., ca. 1.5-3.5 $\mathrm{mg} \mathrm{g}^{-1}$ (Fig. 3), chemical regeneration alone became less effective and ultrasonic treatment had to be used in conjunction with chemical solutions to partially regenerate the CNT. In comparison, thermal treatment seemed to be the most robust approach for CNT regeneration, resulting in efficient recovery of the adsorption capacities of the MWCNT for all compounds and in repeated reuse cycles (Fig. 5).

Despite the promising performance demonstrated by thermal regeneration, there are several technical challenges that need to be overcome for the purpose of full-scale membrane water treatment. Above all, thermal regeneration at $380{ }^{\circ} \mathrm{C}$ or above is not applicable to CNT-polymer composite membranes due to the relatively low melting point for polymeric materials. For example, the PVDF membrane employed in this study has a melting point of $c a .178{ }^{\circ} \mathrm{C}$, and thermal treatment at $380{ }^{\circ} \mathrm{C}$ will cause irreversible damage the membrane structure. Therefore, ceramic membrane that is stable at high temperatures may be employed for the preparation of CNT composite membranes, but this will drive up membrane costs considering the relatively high expense of ceramic membranes.

Overall, the regeneration methods investigated in this study are capable of partially or completely recover the adsorption capacity of CNT for various PPCP compounds, thereby extending the life cycle of MWCNT used as the adsorbents for water treatment. Future work is warranted to optimize the regeneration efficiency, which will allow CNT to become cost-effective sorbents in the predictable future.

\section{Conclusion}

Three regeneration methods, including chemical, ultrasonic and thermal regeneration of MWCNT were compared in this study for dynamic adsorption of pharmaceuticals and personal care products. During the chemical regeneration process, $0.1 \mathrm{M}$ $\mathrm{NaCl}$ solution exhibited the best regeneration result and outperformed methanol and ethanol solutions, possibly by replacing adsorbed PPCP molecules with sodium or chloride ions. In contrast, sonication is capable of enhancing chemical regeneration because collapse of cavitation air bubbles created shear force at $\mathrm{CNT} /$ water interface. As result, the adsorption capacities of the regenerated MWCNT adsorbent for acetaminophen, ibuprofen, and triclosan increased by $4.9-33.7 \%, 36.8-$ $46.9 \%$ and $1.1-6.8 \%$, respectively, as compared to those obtained only with chemical treatment. Moreover, thermal regeneration conducted at $380^{\circ} \mathrm{C}$ vaporized and/or oxidized the three PPCP compounds on CNT surfaces, thus completely recovered the adsorption capacity of CNT in five consecutive reuse cycles. Overall, this study provided baseline information on the efficacy of existing techniques for regenerating CNT adsorbents with intended use of membrane water treatment. Future work is warranted to optimize the regeneration process in order to achieve cost-effective application of CNTs and CNT membranes in the predictable future.

\section{Conflicts of interest}

There are no conflicts to declare.

\section{Acknowledgements}

This research was supported by the State Joint Key Laboratory of Environmental Simulation and Pollution Control of China (Grant No. 2070403GK). Xiuming Wei, Ruochu Zhang, and Yingfeng $\mathrm{Wu}$ were grateful to a Student Innovation Fund awarded by China's Ministry of Education (Grant No. G201510027018).

\section{References}

1 H. P. Singer, A. E. Wössner, C. S. McArdell and K. Fenner, Environ. Sci. Technol., 2016, 50, 6698-6707.

2 D. Shan, S. Deng, T. Zhao, B. Wang, Y. Wang, J. Huang, G. Yu, J. Winglee and M. R. Wiesner, J. Hazard. Mater., 2016, 305, 156-163.

3 F. Liu, S. Chung, G. Oh and T. S. Seo, Three-dimensional graphene oxide nanostructure for fast and efficient watersoluble dye removal, ACS Appl. Mater. Interfaces, 2012, 4, 922-927.

4 X. Cheng, A. T. Kan and M. B. Tomson, Naphthalene adsorption and desorption from aqueous C60 fullerene, $J$. Chem. Eng. Data, 2004, 49, 675-683.

5 F. Liu, J. Zhao, S. Wang, P. Du and B. Xing, Environ. Sci. Technol., 2014, 48, 13197-13206.

6 M. Engel and B. Chefetz, Water Res., 2016, 106, 146-154.

7 Q. Zhang, J. Q. Huang, W. Z. Qian, Y. Y. Zhang and F. Wei, Small, 2013, 9, 1237-1265.

8 Y. H. Li, J. Ding, Z. Luan, Z. Di, Y. Zhu, C. Xu, D. Wu and B. Wei, Carbon, 2003, 41, 2787-2792.

9 A. H. El-Sheikh, J. A. Sweileh, Y. S. Al-Degs, A. A. Insisi and N. Al-Rabady, Talanta, 2008, 74, 1675-1680.

10 H. Wei, S. Deng, Q. Huang, Y. Nie, B. Wang, J. Huang and G. Yu, Water Res., 2013, 47, 4139-4147.

11 P. C. Chiang, E. E. Chang and J. S. Wu, Water Sci. Technol., 1997, 35, 279-285. 
12 Y. Nakano, L. Q. Hua, W. Nishijima, E. Shoto and M. Okada, Water Res., 2000, 34, 4139-4142.

13 J. Wang, X. Peng, Z. Luan and C. Zhao, J. Hazard. Mater., 2010, 178, 125-1127.

14 D. Q. Zhu, S. Hyun, J. J. Pignatello and L. S. Lee, Environ. Sci. Technol., 2004, 38, 4361-4368.

15 R. Ahmad and R. Kumar, J. Chem. Eng. Data, 2010, 55, 34893493.

16 F. M. Machado, C. P. Bergmann, T. H. M. Fernandes, E. C. Lima, B. Royer and T. Calvete, J. Hazard. Mater., 2011, 192, 1122-1131.

17 L. Zhang, J. Lv, T. Xu, L. Yang, X. Jiang and Q. Li, Sep. Purif. Technol., 2013, 116, 145-153.

18 S. Feng, Z. Luo, B. Tao and C. Chen, LWT-Food Sci. Technol., 2015, 60, 970-976.

19 C. Pétrier and A. Francony, Water Sci. Technol., 1997, 35, 175180.

20 G. Cum, G. Galli, R. Gallo and A. Spadaro, Ultrasonics, 1992, 30, 267-270.

21 C. D. Vecitis, G. D. Gao and H. Liu, J. Phys. Chem. C, 2011, 115, 3621-3629.

22 Y. Wang, J. Zhu, H. H. Cho and H. Huang, J. Membr. Sci., 2015, 479, 165-174.

23 Z. H. Li, V. Zlabek, J. Velisek, R. Grabic, J. Machova, J. Kolarova, P. Li and T. Randak, Ecotoxicol. Environ. Saf., 2011, 74, 319-327.

24 T. H. Nguyen, H. H. Cho, D. L. Poster and W. P. Ball, Environ. Sci. Technol., 2007, 41, 1212-1217.

25 B. Wen, M. S. Cao, Z. L. Hou, W. L. Song, L. Zhang, M. M. Lu, H. B. Jin, X. Y. Fang, W. Z. Wang and J. Yuan, Carbon, 2013, 65, 124-139.
26 P. Saini, V. Choudhary, B. P. Singh, R. B. Mathur and S. K. Dhawan, Synth. Met., 2011, 161, 1522-1526.

27 X. Li, J. J. Pignatello, Y. Wang and B. Xing, Environ. Sci. Technol., 2013, 47, 8334-8341.

28 K. Ortiz-Martínez, P. Reddy, W. A. Cabrera-Lafaurie, F. R. Román and A. J. Hernández-Maldonado, J. Hazard. Mater., 2016, 312, 262-271.

29 H. H. Cho, H. Huang and K. Schwab, Langmuir, 2011, 27, 12960-12967.

30 Y. P. Chin, G. Aiken and E. O'Loughlin, Environ. Sci. Technol., 1994, 28, 1853-1858.

31 M. A. Zazouli, H. Susanto, S. Nasseri and M. Ulbricht, Water Res., 2009, 43, 3270-3280.

32 W. L. Jorgensen and D. L. Severance, J. Am. Chem. Soc., 1990, 11(2), 4768-4774.

33 P. Mignon, S. Loverix, J. Steyaert and P. Geerlings, Nucleic Acids Res., 2005, 33, 1779-1789.

34 A. Tiehm, K. Nickel, M. Zellhorn and U. Neis, Water Res., 2001, 35, 2003-2009.

35 T. J. Mason, Practical Sonochemistry User's Guide to Application in Chemistry and Chemical Engineering, Ellis Horwood, UK, 1991.

36 G. Portenlänger, Mechanical and radical effects of ultrasound, in Ultrasound in Environmental Engineering, TU Hamburg-Harburg Reports on Sanitary Engineering, 1999, vol. 25, pp. 139-151.

37 K. R. Moonoosawmy and P. Kruse, Cause and Consequence of Carbon Nanotube Doping in Water and Aqueous Media, $J$. Am. Chem. Soc., 2010, 132, 1572-1577. 